UNIMAS E-Journal of Civil Engineering, Vol. 1 (2) /April 2010

\title{
Effect of seawater on the properties of Epoxy Modified Concrete
}

\author{
Timmy Jupiter ${ }^{1}$, Azida Hj Rashidi ${ }^{2}$ and Idawati Ismail ${ }^{2}$
}

\begin{abstract}
Epoxy is the most common type of polymer used by civil engineers to produce Polymer Cement Concrete (PCC). In this study, the effect of seawater on epoxy modified mortar in the Malaysian seawater is investigated using PCC mixes with Epoxy is used as the cement replacement. Fifteen 100x100x100 mm standard cubes were casted from five different mixes. The samples range from 5\% to 50\% epoxy replacement to cement content by weight ratio. Samples were placed in sea water and tap water for 100 days and monitored for short-term durability aspects such as physical changes in weight, appearances and absorption percentages. Compressive strength for 7, 14, 28 and 100 days were also taken. Results were compared with control samples having 0\% epoxy. Results show that the strength of samples depends on the amount of epoxy used. The absorption test results can be an initial indicator to the durability properties of concrete material. It was also found that PCC with $20 \%$ epoxy can effectively reduce overall deterioration of concrete especially those exposed to sea water.
\end{abstract}

Keywords:

Epoxy modified concrete, sea water, absorption, compressive strength,

\section{Introduction}

$\mathrm{U}$ tilization of conventional mortar and concrete made with Portland cement as popular construction material cannot be doubted. However, they have some disadvantages such as delayed hardening, low tensile strength, high drying shrinkage, susceptibility to frost damage, low chemical resistance and especially, chemical attack in marine environment [1]. Hence, polymers or resin (commercial polymer) instead or as part replacement of Portland cement have been added to reduce these disadvantages [1].

\section{Polymer Modified Concrete}

Polymer cement concrete or sometimes called polymer-modified concrete is a modified concrete in which part of the cement binder is replaced by a synthetic organic polymer admixtures [2]. The polymeric admixtures or cement modifiers are relatively new materials which improve strength, durability, resistance to corrosion, water permeability and resistance to damage from freeze-thaw cycles [1]. Examples of the polymers used are latexes or emulsions, dispersible polymer powders, water-soluble polymers, liquid Resin and monomers such as Epoxy. Epoxy as part of cement replacement to produce epoxy modified mortar and concrete can be more expensive compared to the latex-modified mortar and concrete. However, epoxy modified mortar and concrete is gaining increasing acceptance in the construction industry because of their good cost-performance balance as well as give more rapid hardening, higher thermal stability, better flexural strength, modulus of elasticity and better water resistance can be obtained. Other liquid polymer-modified mortar and concrete still require further laboratory testing and on-site experiences. [3].

Due to the improved properties, polymer cement concrete is being used in the construction industry and repair of highways and structures such as floors, bridge decks, road surfacing.[1-4].

\footnotetext{
${ }^{1}$ Student, Department of Civil Engineering, Faculty of Engineering, Universiti Malaysia Sarawak, 94300-Kota Samarahan, Sarawak, Malaysia.
}

${ }^{2}$ Lecturer, Department of Civil Engineering, Faculty of Engineering, Universiti Malaysia Sarawak, 94300-Kota Samarahan, Sarawak, Malaysia, 
Extensive works have been done in understanding the properties of epoxy cement concrete, applications in harsh environments, high temperature and repair works [8][9][10]. Epoxy is used in the investigation of sea-water effect on epoxy-repaired concrete [5][6]. Performance of epoxy modified concrete exposed to highly concentrated chloride and sulphate below ground conditions in coastal area was done by $\mathrm{M}$. A.Bader [2003]. With the harsh environment of high salt concentration and low quality local construction materials, it was found that the performance of latex and epoxy modified concrete was better than that of polymer concrete. Some works have also been done on marine structures in Malaysia [8].

\section{Research significance}

The effect of seawater on epoxy modified mortar in the Malaysian seawater is investigated in this study. An optimum design mix using locally available epoxy resin is investigated to give optimum strength as well as acceptable durability criteria when exposed to marine environment. The criteria are the physical changes in weight and appearances and water/seawater absorption percentages. Compressive strength for 7, 14, 28 and 100 days were also taken. Results were compared with control samples having $0 \%$ epoxy in the mix.

\section{Experimental works}

\subsection{Materials}

The materials used in this study were ordinary Portland cement, fine sand $(0.07 \mathrm{~mm}$ sieve analysis), Epoxy resin (hardener and resin) and tap water.

\subsection{Casting and Mixing}

The mixes were prepared by weight proportion with epoxy is used as a cement replacement material. A total 72 cube samples of $100 \mathrm{~mm}$ X $100 \mathrm{~mm} \mathrm{X} \mathrm{100mm} \mathrm{size} \mathrm{were} \mathrm{prepared} \mathrm{from} \mathrm{six} \mathrm{different} \mathrm{mixes.}$ Five mixes (EP5, EP10, EP15, EP20 and EP50) have different epoxy contents, with EP5 having 5\% of epoxy resin by weight of cement; while CM, is the control mix with $0 \%$ of epoxy resin. Table 1 shows the different specimens with their mix proportions.

Table1. Mix Proportion used

\begin{tabular}{|c|c|c|c|c|c|}
\hline Mix & Epoxy content as part of cement replacement & Cement & w/c & Epoxy & Sand \\
\hline EP5 & $5 \%$ & 45 & 0.54 & 5 & 50 \\
\hline EP10 & $10 \%$ & 40 & 0.45 & 10 & 50 \\
\hline EP15 & $15 \%$ & 35 & 0.4 & 15 & 50 \\
\hline EP20 & $20 \%$ & 30 & 0.3 & 20 & 50 \\
\hline EP50 & $50 \%$ & 0 & 0 & 50 & 50 \\
\hline CM & Control Mix & 50 & 0.5 & 0 & 50 \\
\hline
\end{tabular}




\subsection{Method of casting}

The use of epoxy compounds in preparing concrete can be difficult because the compound begins to set once the hardener and resin mix together. Therefore, other materials are pre-prepared and thoroughly mixed before adding the epoxy compound.

Casting is done quickly in 100x100x100 mm cubes. All the samples were cured in a curing tank to make sure that maximum hydration process within the sample can take place [7]

The tests carried out in this project were the weight and density test, compression tests, absorption and durability check due to sea water and tap water.

\section{Results and Discussion}

\subsection{Weight and density}

An average weight from 3 cube samples at age of 0 days was obtained for each mix. Then, an average dry density from 3 cube samples for each mix was calculated using the cube volume. Average weight and density of each mix are shown in Figure1.

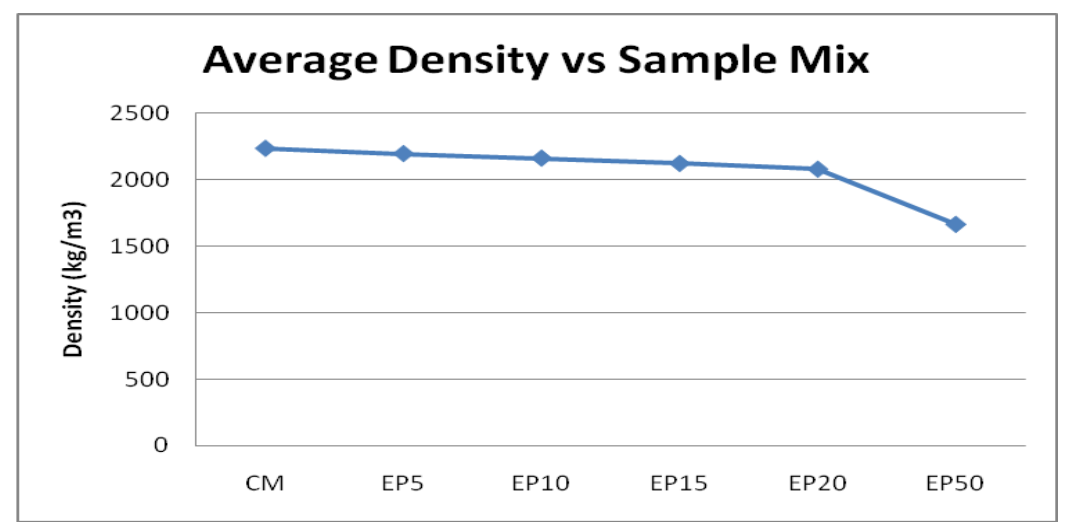

Figure 1: Density of Specimen against the Percentage Epoxy used

It is found that as the percentage of epoxy replacement increases, the weight and density of the specimen decreases accordingly in a linear manner. The decrease in weight is because the epoxy has lower density than cement. Figure 1 shows with increase in epoxy replacement, the possibility of achieving a lightweight concrete material is possible.

\subsection{Compressive strength}

The compressive strength tests from 3 cube samples for each mix were done when the cubes are of 7 days, 14 days, 28 days and 100 days of age.

Table 2 shows that the average compressive strength at 28 days increases with increase in epoxy percentage replacement. The strength increase may be due to cement hydration and increased percentage of epoxy particles flocculating into continuous film at the same time. 
UNIMAS E-Journal of Civil Engineering, Vol. 1 (2) /April 2010

Table 2: Compressive Strength at 28 days for the different mixes

\begin{tabular}{|c|c|}
\hline Specimen & Average Compressive strength at 28days $\left(\mathrm{N} / \mathrm{mm}^{2}\right)$ \\
\hline CM & 50.31 \\
\hline EP5 & 51.17 \\
\hline EP10 & 54.14 \\
\hline EP15 & 57.02 \\
\hline EP20 & 58.25 \\
\hline EP50 & 64.37 \\
\hline
\end{tabular}

Figure 2 shows the percentage of rate increase in strength of the different specimen. Specimen with $0 \%$ epoxy shows a higher initial strength increase and E50 has the least strength increase. This means that the specimen with $0 \%$ epoxy has highest initial cement hydration process since it has highest cement percentage. Other samples have lesser cement content but with time, continue to increase in strength due to cement hydration and at the same time, epoxy particles coalescing into continuous film. This shows that epoxy resin does not affect the hydration process of the cement materials. The percentage of strength increase are highlighted in Table 4

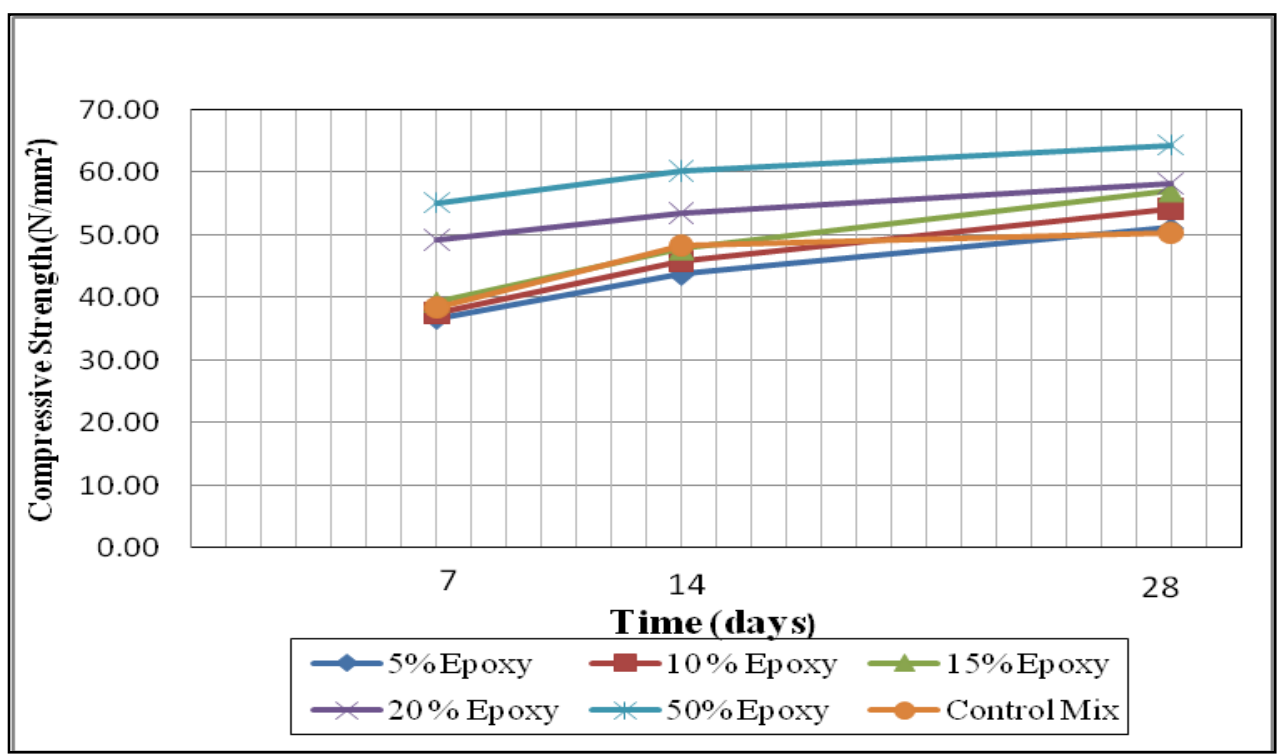

Figure 2: Graph of compressive strength of different mix vs time (days)

Table 4: Rate of strength increase for different epoxy replacement

\begin{tabular}{|c|c|c|}
\hline Specimen & $\begin{array}{c}\text { 14days Strength increase } \\
(\%)\end{array}$ & $\begin{array}{c}\text { 28days Strength increase } \\
(\%)\end{array}$ \\
\hline CM & 26.23 & 4.09 \\
\hline E5 & 19.31 & 17.41 \\
\hline E10 & 22.61 & 18.45 \\
\hline E15 & 21.76 & 19.51 \\
\hline E20 & 9.93 & 8.65 \\
\hline E50 & 9.22 & 6.82 \\
\hline
\end{tabular}




\subsection{Tap Water and Seawater Absorption and post- compressive strength}

Three cube samples from each mix were oven-dried until no change in the specimens' weight was observed. Then, the samples were soaked in a curing tank filled with seawater for about 100 days. Then, weights for three cube samples from each mix are recorded at least three times a week during the 100 days duration to get an average weekly absorption value per mix. Similar procedure is also done for samples soaked in a curing tank filled with tap water as control test. The samples absorption capacities results in sea water are then compared to results from the control test. Physical and colour changes are also observed. Compressive strength for the specimens soaked in seawater after the 28 days duration was also noted.

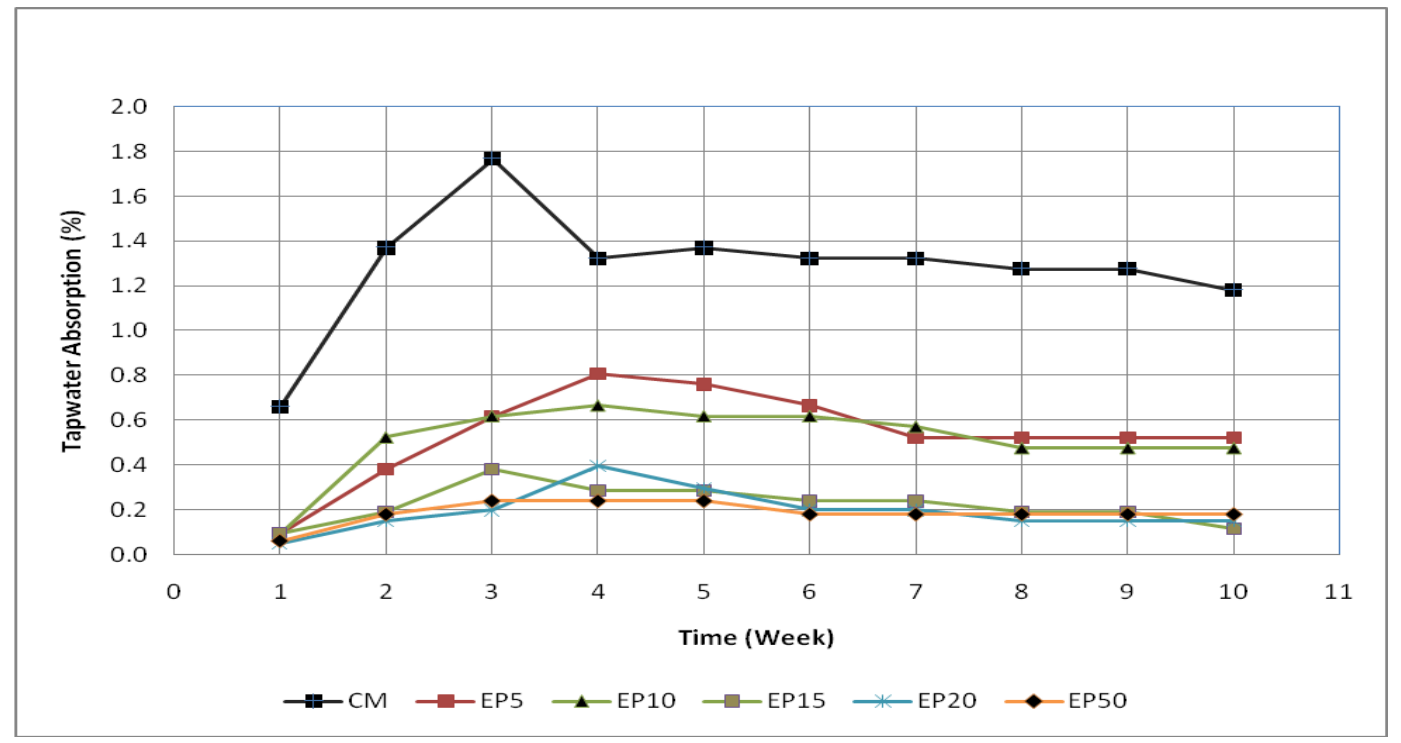

Figure 4.3 shows the relationship of water absorption with time for different mix proportion in tap water.

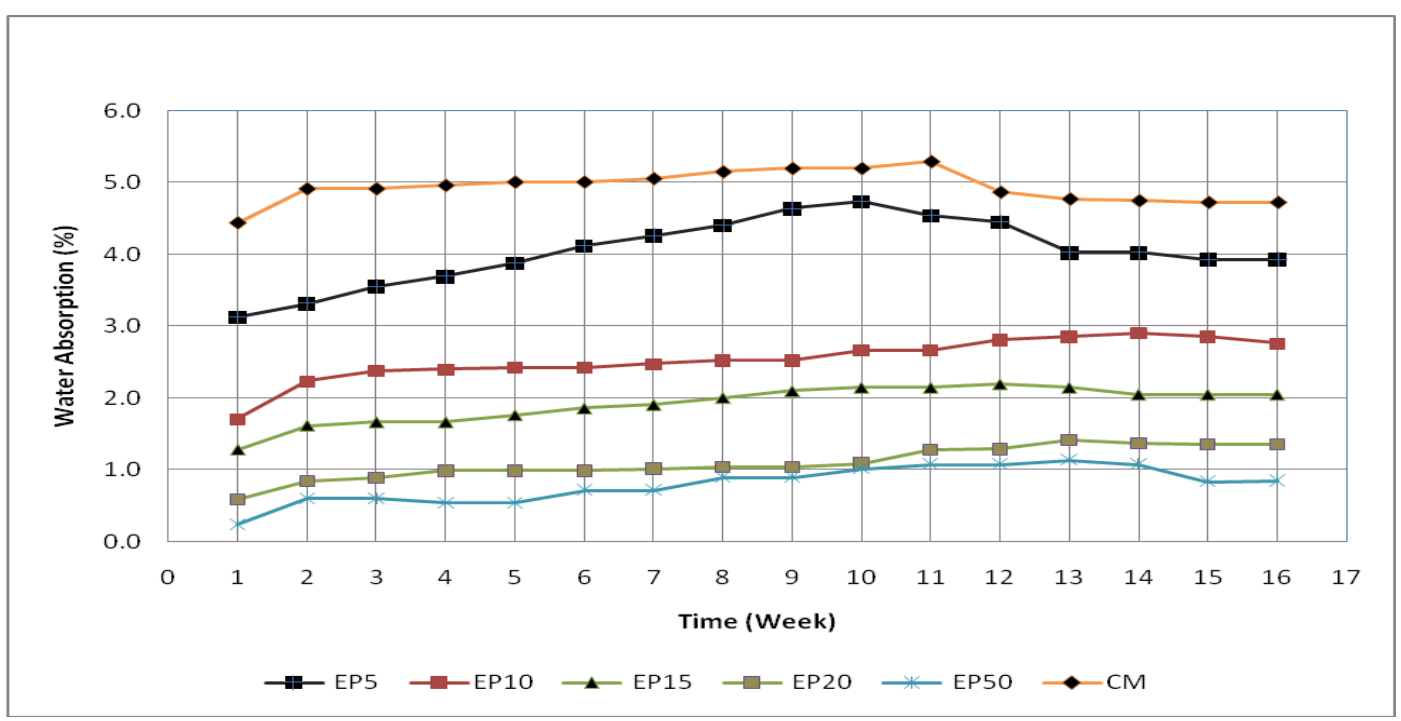

Figure 4.4 shows the water absorption with time for different mix proportion in sea water. 
From Figure 4.3 and 4.4, it can be concluded that specimens with $0 \%$ epoxy have the highest absorption properties. Absorption properties gradually decrease with increase in Epoxy percentages in the specimens with E50 has the least absorption properties in both sea water $(0.19 \%)$ and tap water $(0.972 \%)$. It is also found that the specimens absorb more seawater than the tap water.

Figure 4.5 shows the comparison of compressive strength of different mix proportion soaked in sea water after 100 days. It is found that the compressive strength of the specimens soaked in sea water have reduced quite drastically. The specimen with $0 \%$ epoxy has a $16.1 \%$ strength reduction and specimen with $50 \%$ epoxy has the least reduction of $1.2 \%$.

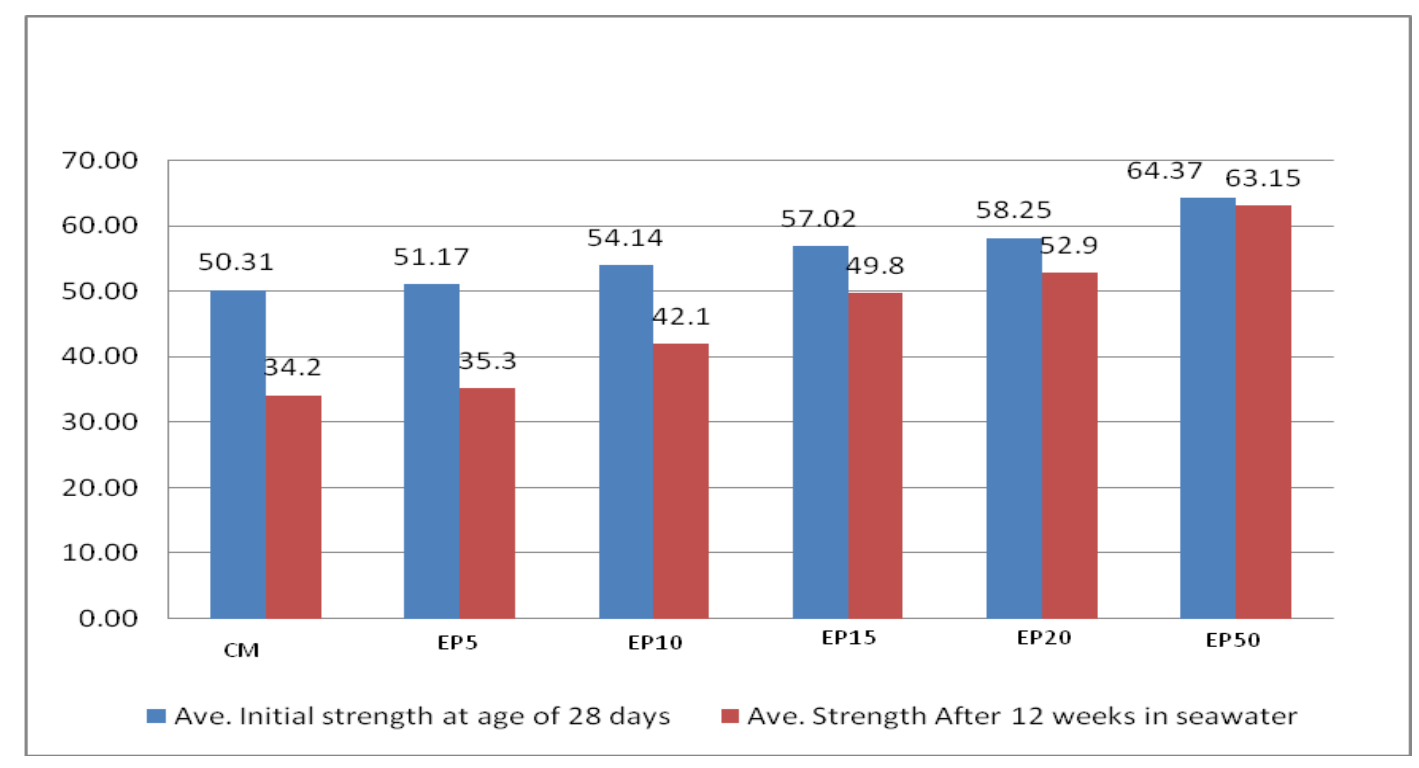

Figure 4.5 Comparison in compressive strength of samples in seawater after 12 weeks.

The strength of the specimen soaked in sea water is reduced as the seawater contains dissolved salts which react with concrete. Figure 4.6 shows the typical physical condition of the sample, EP0, with some cavities created on the surface of the specimen at 100 days. 


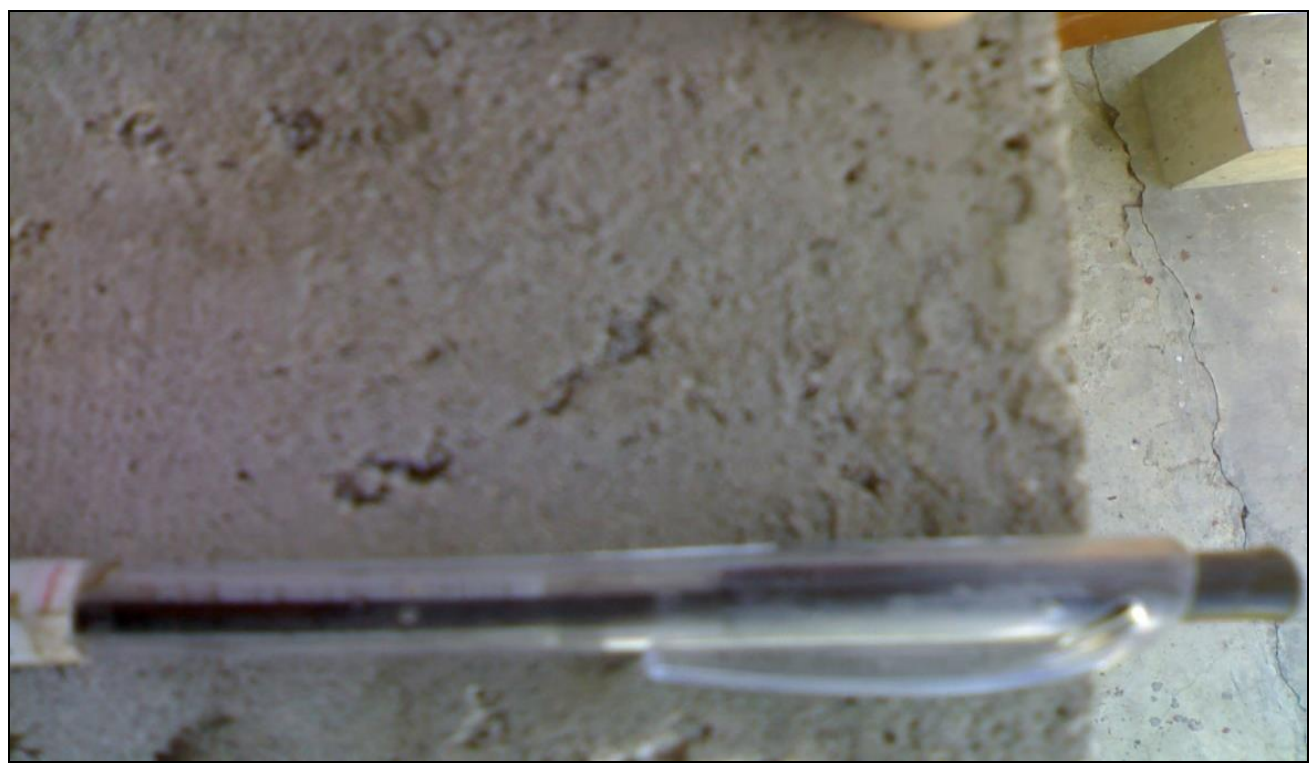

Figure 4.6 shows the physical changes of sample, EP0, after being immersed in seawater for 100days.

Results from the seawater test shows that seawater can cause concrete to deteriorate. Leeching of concrete surfaces occurs when it is exposed to seawater for certain period of time.

The replacement of cement binder by epoxy resin by some percentage can slow down the deterioration of concrete due to water penetration. In the initial stage, epoxy compound produces fine epoxy flocculation; then gradually form a continuous film/layer towards later stage while at the same time, the cement undergoes the hydration process. Water is prevented to seep through the fine pores due to the epoxy layer of the specimen; thus making it impermeable. This is evident from the lower percentage of water absorption by epoxy modified concrete specimens, E5 to E50, compared to the specimens with zero epoxy.

Seawater contains sulphates, magnesium, and chloride ions. Sulphates ions can bleach away the hydrated cement paste and exposed the aggregates. This type of deterioration leads to reduction in crosssectional area of the structural component.

\section{Conclusion}

The conclusions drawn from this study and summarized below are applicable to the characteristics of the materials used and the range of parameters investigated: (i) the strength of samples increases as the percentage of epoxy used is increased (ii) As the percentage of epoxy used is increased, the percentage of water and sea water absorption decreases (iii) Sea water affects the compressive strength of concrete more than tap water (iv) concrete with highest percentage of epoxy as the least affected by seawater. (v) $20 \%$ epoxy is the optimum percentage cement replacement in epoxy cement concrete and can effectively reduce overall deterioration of concrete especially those exposed to sea water.

\section{References}

[1] Yoshihiko O., 'Handbook of polymer-modified concrete and mortars', 246 pages, Dec 1995. Isbn-13:978-0-8155-1358-2

[2] Blaga A. et al, 'Polymer Modified concrete', Canadian Building Digest-241, October 1985

[3] Yoshihiko O., 'Polymer-based Admixtures', Cement and Concrete Composites Vol.20, 189-212, 1998.

[4], Use of Epoxy compounds with concrete, ACI 503R-93 Reapproved 1998 


\section{UNIMAS E-Journal of Civil Engineering, Vol. 1 (2)/April 2010}

[5] El-Hawaary et al., 'Effect of sea water on epoxy-repaired concrete', Cement and Concrete Composites, Vol.20, n1, p41-52 Feb 2000

[6] El-Hawaary et al.; 'Performance of epoxy-repaired concrete in a marine environment', Cement and Concrete Composites, Vol. 30, 2000, pp 259-266

[7] Maher A.B., 'Performance of concrete in a coastal environment', Cement and Concrete Composites, Volume 25, Issues 4-5, May-July 2003, Pages 539-548

[8]Sallehuddin S.A et al., 'Condition Assessment of Marine Structures Using Functional Condition Index Approach', Malaysian Journal of Civil Engineering,Vol.18 (2). pp. 129-138, 2006

[9] Raff R.A.V et al., Epoxy Polymer Modified concrete', Polymer in Concrete, 1973,.339-45,

[10] El-Hwary, M.M et al., 'On the mechanical properties of polymer Portland cement concrete, Journal of the Chinese Institute of Engineers, Transactions of the Chinese Institute of Engineers, Series A/Chung-kuo Kung Ch'eng Hsuch K'an, Vol. 28, Issue 1, $155-159,2005$ 